Jurdimas (Jurnal Pengabdian Kepada Masyarakat) Royal

Vol. 5 No. 1, Januari 2022, hlm. 7 - 12

ISSN 2614-7912 (Print)

DOI: https://doi.org/10.33330/jurdimas.v5i1.1097

ISSN 2622-3813 (Online)

Available online at https:/jurnal.stmikroyal.ac.id/index.php/jurdimas

\title{
SOSIALISASI ILMU STATISTIK DALAM PENELITIAN BAGI MAHASISWA DI KOTA PALEMBANG
}

\author{
Muhammad Bahrul Ulum ${ }^{1 *}$, Ayu Geby Gisela Syaputri ${ }^{2}$ \\ ${ }^{1}$ Program Studi Manajemen Universitas Indo Global Mandiri \\ ${ }^{2}$ Program Studi Manajemen Universitas Muhammadiyah Palembang \\ email: bahrulu1994@uigm.ac.id
}

\begin{abstract}
Statistics and research are two things that cannot be separated. Although there are types of research that do not require the dominant role of statistics (qualitative research), but to be able to produce conclusions that can be generalized to a wider population, statistics is needed. Such research is quantitative research with a positivistic paradigm, ie a phenomenon is real if it can be seen, measured, and classified. The application of statistical science which is generally needed by students in writing research such as theses and theses, will have a positive impact, especially in improving the quality of the research. To achieve this goal, it is necessary to conduct socialization to students. The socialization was carried out to several students from both state universities and private universities in the city of Palembang. The socialization was done by introducing and giving tutorials on how to use statistical applications such as SPSS and Eviews, because several lecturers at several universities in Palembang complained about the poor quality of research and some said that their students did not really understand how to use SPSS and Eviews. The first result of this service is that students' understanding of SPSS and Eviews can be seen from discussions and questions and answers, second, namely the ability of students to apply the use of SPSS and Eviews in research.
\end{abstract}

Keywords: research; socialization; statistics

\begin{abstract}
Abstrak: Statistik dan penelitian merupakan dua hal yang tidak bisa dipisahkan. Meskipun ada jenis penelitian yang tidak membutuhkan peranan statistika yang dominan (penelitian kualitatif), namun untuk dapat menghasilkan kesimpulan yang dapat digeneralisasikan ke populasi yang lebih luas diperlukan ilmu statistika. Penelitian yang demikian adalah penelitian kuantitatif dengan paradigma yang positivistik, yakni suatu gejala itu adalah nyata jika bisa dilihat, diukur, dan diklasifikasikan. Penerapan ilmu statistik yang umumnya dibutuhkan mahasiswa dalam penulisan penelitian seperti skripsi dan tesis, akan berdampak positif terutama dalam meningkatan kualitas penelitian tersebut. Untuk mencapai tujuan tersebut maka perlu diadakan sosialisasi kepada mahasiswa. Sosialisasi dilakukan pada beberapa mahasiswa baik dari perguruan tinggi negeri maupun perguruan tinggi swasta di Kota Palembang. Sosialisasi dilakukan dengan cara mengenalkan dan memberikan tutorial bagaimana penggunaan aplikasi statistic seperti, SPSS dan Eviews, karena beberapa dosen di beberapa universitas di Palembang mengeluhkan buruknya kualitas penelitian dan ada juga yang mengatakan bahwa mahasiswa mereka tidak begitu mengerti cara penggunaan SPSS dan Eviews. Hasil dari pengabdian ini yang pertama adalah pemahaman mahasiswa mengenai SPSS dan Eviews dapat dilihat dari diskusi dan tanya jawab, kedua yaitu kemampuan mahasiswa dalam menerapkan penggunaan SPSS dan Eviews dalam penelitian.
\end{abstract}

Kata Kunci: penelitian; sosialisasi; statistik

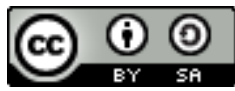


Jurdimas (Jurnal Pengabdian Kepada Masyarakat) Royal

Vol. 5 No. 1, Januari 2022, hlm. 7 - 12

ISSN 2614-7912 (Print)

DOI: https://doi.org/10.33330/jurdimas.v5i1.1097

ISSN 2622-3813 (Online)

Available online at https:/jurnal.stmikroyal.ac.id/index.php/jurdimas

\section{PENDAHULUAN}

Penggunaan istilah statistika berakar dari istilah-istilah dalam bahasa latin modern statisticum collegium ("dewan negara") dan bahasa Italia statista ("negarawan" atau "politikus"). Gottfried Achenwall menggunakan Statistik dalam bahasa Jerman untuk pertama kalinya sebagai nama bagi kegiatan analisis data kenegaraan, dengan mengartikannya sebagai "ilmu tentang negara (state)" (Rizki, Ammar, Fajriyah, \& Fasya, 2021). Pada awal abad ke-19 telah terjadi pergeseran arti menjadi "ilmu mengenai pengumpulan dan klasifikasi data". Sir John Sinclair memperkenalkan nama (Statistics) dan pengertian ini ke dalam bahasa Inggris. Jadi, statistika secara prinsip mula-mula hanya mengurus data yang dipakai lembagalembaga administratif dan pemerintahan. Pengumpulan data terus berlanjut, khususnya melalui sensus yang dilakukan secara teratur untuk memberi informasi kependudukan yang berubah setiap saat (Rudini, 2017).

Dewasa ini hampir semua penelitian dilakukan dengan pendekatan kuantitatif. Dalam membuat perencanaan, pelaksanaan, dan penafsiran dari banyak penelitian menjadi semakin tergantung pada metodologi penelitian statistika. Oleh karena itu, penguasaan ilmu statistika menjadi syarat yang sangat perlu bagi seorang peneliti (Pradipta, 2016). Dalam pelaksanaan penelitian, seorang peneliti perlu memiliki kemampuan meneliti, dan salah satu kemampuan tersebut adalah penguasaan ilmu statistik. Kurangnya pengetahuan mengenai ilmu statistik dapat menyebabkan seorang peneliti membuat beberapa kesalahan antara lain kesalahan menyusun hipotesis yang hendak diuji, kesalahan menentukan sampel, kesalahan memilih teknik statistika yang sesuai dengan tujuan dan hipotesis penelitian, dan kesalahan menginterpretasikan hasil analisis (Rosadi \& Suputra, 2017).

Menurut (Darmadipura et al. \& Juneman,2018) dalam penelitiannya mengemukakan, ada sebelas jenis kesalahan penggunaan statatistik sebagai alat analisis, baik dalam desain maupun analisis yang sering dilakukan dalam penelitian klinis yang ditemukan dalam jurnal kedokteran terkemuka. Hal yang sama ditemukan dalam beberapa penelitian mahasiswa di berbagai jurusan perkuliahan.

Dalam sebuah penelitian, statistika berperan sebagai ilmu yang menyediakan berbagai macam alat analisis untuk membantu memecahkan masalah yang diselidiki, sedangkan di pihak lain statistika dibutuhkan sebagai alat bantu untuk memahami atau menelaah tulisan-tulisan ilmiah seperti dalam artikel dan buku. Peran penting ilmu statistik dalam penelitian diungkapkan oleh (Safitriani, 2019) bahwa alasan mengapa statistika penting dalam penelitian, yaitu bahwa statistika sangat memungkinkan deskripsi yang lebih pasti, statistika membuat peneliti untuk serba jelas dan pasti baik dalam prosedur maupun pemikirannya, statistika memungkinkan peneliti merangkum temuannya dalam bentuk yang lebih jelas dan bermakna, statistika memungkinkan peneliti untuk menarik kesimpulan, memprediksi, dan menelaah berbagai faktor sebab-akibat yang melingkupi atau mendasari kejadiankejadian yang kompleks. Statistik dalam sebuah penelitian juga digunakan untuk mendapatkan kesahihan data itu sendiri dalam suatu penelitian, karena penelitian merupakan cara ilmiah untuk 
Available online at https:/jurnal.stmikroyal.ac.id/index.php/jurdimas

mendapatkan data dengan tujuan yang sudah ditentukan sebelumnya, baik terkait korelasi, efektifitas, analisis, perbandingan dan lain sebagainya (Kurniasih, 2020).

Selain itu, statistika juga merupakan cabang ilmu matematika terapan yang terdiri dari teori dan metoda mengenai bagaimana cara mengum-pulkan, mengukur, mengklasifikasi, menghitung, menjelaskan, mensintesis, menganalisis, dan menafsirkan data yang diperoleh secara sistematis. Dengan demikian, didalamnya terdiri dari sekumpulan prosedur mengenai bagaimana cara mengumpulkan data, meringkas data, mengolah data, menyajikan data, menarik kesimpulan dan interpretasi data berdasarkan kumpulan data dan hasil analisisnya (Rahim, 2013).

Dalam pandangan (Sholikhah, 2016) mengungkapkan peran statistika dalam langkah-langkah penelitian adalah dalam penyusunan model teoretis, penyusunan rumusan hipotesis, pengembangan alat pengumpul data, penyusunan rancangan penelitian, penentuan sampel penelitian, serta pengolahan dan analisis data. Menurut (Herawati \& Rantello, 2020) dalam suatu penelitian unsur-unsur metodologi yang berkaitan dengan statistika (selanjutnya disebut metodologi statistika) adalah rumusan hipotesis (jika ada), penentuan populasi dan sampel, tehnik analisis statistika/statistik uji atau rancangan, interpretasi hasil.

Dalam statistik, ada dua pendekatan untuk menganalisis informasi berdasarkan jenis informasi yang diperoleh, yaitu analisis kuantitatif dan analisis kualitatif. Analisis kuantitatif/ analisis data kuantitatif adalah analisis yang berbasis pada kerja hitung-menghitung angka. Angka yang diolah disebut input dan hasilnya disebut output juga berupa angka. Analisis kualitatif/analisis data kualitatif adalah analisis yang berbasis pada kerja pengelompokan simbol-simbol selain angka. Simbol itu berupa kata, frase, atau kalimat yang menunjukkan beberapa kategori. Input maupun output analisis data kualitatif berupa simbol, dimana outputnya disebut deskripsi verbal (Nurizzati, 2015).

Di kalangan mahasiswa, penggunaan ilmu statistik sangatlah penting terutama bagi mahahasiswa yang akan menulis penelitian. Penguasaan alat analisis statistik seperti SPSS dan Eviews tentu akan sangat membantu dalam menulis sebuah penelitian. Berdasarkan informasi beberapa dosen yang mengajar di kampus-kampus di kota Palembang kualitas penelitian mahasiswa masih belum begitu baik. Hal ini karena mayoritas mahasiswa belum terlalu mengerti cara penggunaan alat analisis statistik.

Dalam rangka meningkatkan kualitas penyelenggaraan tridharma perguruan tinggi oleh Universitas Indo Global Mandiri khususnya dalam dharma pengabdian, maka dilaksanakanlah sosialisasi ilmu statistik yang ditujukan untuk mahasiswa di kota Palembang agar kedepannya dapat meningkatkan pengetahuan para mahasiswa mengenai pentingnya ilmu statistik untuk suatu penelitian.

\section{METODE}

Kegiatan Pengabdian kepada Masyarakat ini dilaksanakan pada tanggal 1-30 September 2020 dari mulai menyiapkan proposal hingga menyelesaikan laporan di Telkomsel Smart Office Palembang yang 
Available online at https://jurnal.stmikroyal.ac.id/index.php/jurdimas

belokasikan di Jl. Veteran No.88A, Kuto Batu, Kec. Ilir Tim. II, Kota Palembang, Sumatera Selatan 30114. Kegiatan ini diikuti oleh 36 peserta. Untuk menunjang acara kegiatan Pengabdian kepada Masyarakat ini dan mencapai tujuannya, maka kegiatan Pengabdian kepada Masyarakat menerapkan beberapa metode, diantaranya:

\section{Pendidikan Masyarakat}

Metode ini digunakan terlebih dahulu karena agar mahasiswa dapat memahami kebutuhan publikasi karya ilmiah di Indonesia saat ini dan beberapa manfaat dari penelitian. Para mahasiswa juga akan diberikan beberapa contoh dan trik untuk menemukan ide-ide atau topik-topik menarik untuk dijadikan sebuah penelitian. Tujuannya adalah agar para mahasiswa memahami betul peranan mereka sebagai masa depan bangsa dan juga diharapkan agar merasa termotivasi untuk melakukan penelitian karena meneliti memberikan banyak manfaat, seperti menembah pengetahuan dan meningkatkan wawasan.

\section{Pratest}

Setelah menjelaskan pengenai penelitian/riset, selanjutnya adalah kegiatan sosialisasi dimulai dengan pemberian Quisioner Pra Test untuk mengetahui seperti seberapa besar pengetahuan peserta (mahasiswa) menenai statistik untuk penelitian.

\section{Diskusi}

Sesi tanya jawab untuk berdiskusi dan memberikan solusi bagi para mahasiswa yang belum paham. Pengabdian kepada Masyarakat ini bertujuan untuk membantu para mahasiswa melakukan penelitian dengan lebih baik dan efisien, yaitu dengan menggunakan aplikasi SPSS dan
Eviews, agar karya ilmiah yang dihasilkan akan lebih berkualitas.

\section{PEMBAHASAN}

Kegiatan Pengabdian kepada Masyarakat ini ini terbagi menjadi dua sesi, yaitu sesi pemaparan materi, serta praktik menggunakan SPSS dan Eviews, dan sesi tanya jawab para peserta.

\section{Pemaparan Materi}

Kegiatan pertama, para mahasiswa diberi materi terlebih dahulu. Materi-materi yang akan disampaikan adalah manfaat ilmu statistik untuk penelitian, dan bagaimana mencari ide atau topik-topik menarik dalam penelitian, serta praktek penggunaan SPSS dan Eviews kemudian mahasiswa diberi quisioner untuk mengetahui sejauh mana mahasiswa memahami mengenai materi yang telah disampaikan.

Berdasarkan hasil Pra Test, Pemateri akan mengarahkan dan memberikan pemahaman untuk meningkatkan pengetahuan dan kemampuan peserta terhadap penerapan ilmu statistik dengan menggunakan aplikasi statistik, seperti SPSS dan Eviews. Kegiatan ini berkerja sama dengan telkomsel sebagai host tempat penyelenggaraan acara dan juga bantuan satu dosen dari Fakultas Ekonomi Universitas Muhammadiyah Palembang.

\section{Tanya Jawab}

Setelah pemaparan selesai, kegiatan selanjutnya adalah tanya jawab, dalam kegiatan ini mahasiswa cukup antusias karena beberapa di antara mereka adalah mahasiswa semester akhir yang akan menulis penelitian. 


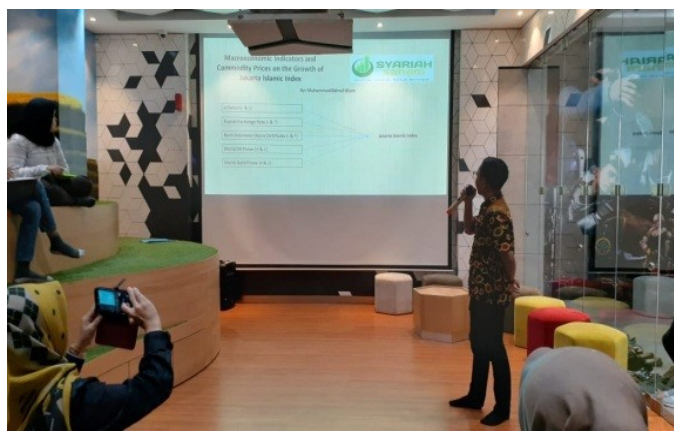

Gambar 1. Pemaparan Materi

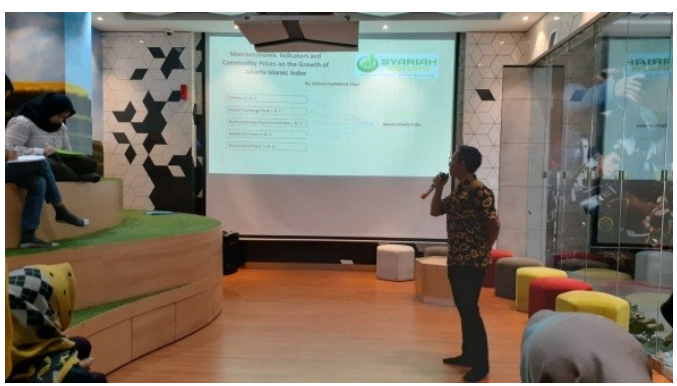

Gambar 2. Pemaparan Materi

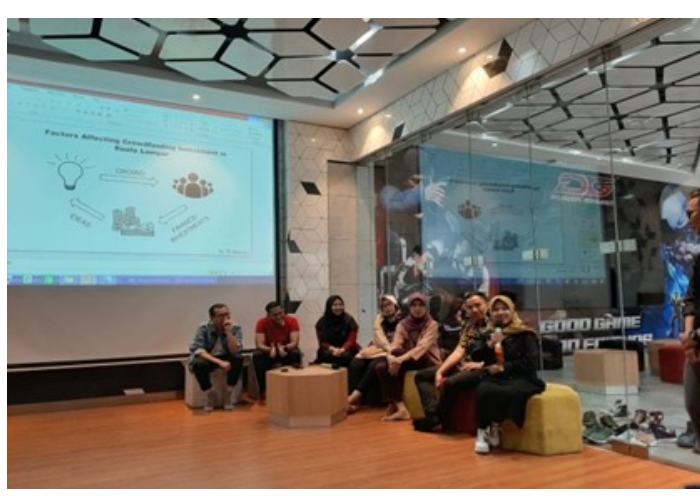

Gambar 3. Sesi Tanya Jawab

\section{SIMPULAN}

Kegiatan tridharma Pengabdian kepada Masyarakat yang dilaksanakan bagi para mahasiswa di kota Palembang berjalan dengan baik. Kegiatan sosialisasi ini memberikan tambahan pengetahuan bagi para mahasiswa terutama mengenai penerapan ilmu statistik dalam penelitian. Sikap antusias dari para mahasiswa tercermin dalam sesi tanya jawab.

\section{DAFTAR PUSTAKA}

Darmadipura, M. S., Syukriani, Y., Sachrowardi, Q., Basbeth, F., Fitrasanti, B. I., Juneman, ... Irmansyah. (2018). Isu Etik Dalam Penelitian di Bidang Kesehatan.

Herawati, N., \& Rantello, A. T. (2020). Pengaruh Gaya Kepemimpinan Terhadap Kepuasan Kerja Karyawan pada PT JMS Jakarta. Jurnal Ekonomi,Sosial \& Humaniora, 01(10), 1-14.

Kurniasih, N. (2020). Peran Statistik Dalam Penelitian. Al-Munqidz: Jurnal Kajian Keislaman, 2(17), 273-279.

Nurizzati, Y. (2015). Peranan statistika dalam penelitian sosial ekonomi. 91-105.

Pradipta, R. N. (2016). Pengaruh Lingkungan Kerja Dan Disiplin Kerja Terhadap Kinerja Pegawai. Jurnal Manajemen Indonesia, 4(1).

Rahim, A. (2013). STATISTIKA DALAM PENELITIAN PENDIDIKAN. Jurnal Edukasi.

Rizki, M. I., Ammar, T., Fajriyah, F., \& Fasya, S. (2021). Peramalan Indeks Harga Saham PT Verena Multi Finance Tbk Dengan Metode Pemodelan ARIMA Dan ARCH-GARCH. Jurnal Ilmiah Teori Dan Aplikasi Statistika, 14(1), 1123.

doi: https://doi.org/10.36456/jstat.vo 114.no1.a3774

Rosadi, A. I., \& Suputra, I. D. G. D. (2017). Pengaruh Kinerja Keuangan, Dana Alokasi Umum Dan Silpa Pada Alokasi Belanja Modal. E-Jurnal 
Jurdimas (Jurnal Pengabdian Kepada Masyarakat) Royal

Vol. 5 No. 1, Januari 2022, hlm. 7 - 12

ISSN 2614-7912 (Print)

DOI: https://doi.org/10.33330/jurdimas.v5i1.1097

ISSN 2622-3813 (Online)

Available online at https://jurnal.stmikroyal.ac.id/index.php/jurdimas

Akuntansi, 19(2), 1144-1173.

Rudini, R. (2017). Peranan Statistika Dalam Penelitian Sosial Kuantitatif. Jurnal SAINTEKOM, 6(2), 53. doi: 10.33020/saintekom.v6i2.13

Safitriani, S. (2014). Perdagangan Internasional Dan Foreign Direct Investment Di Indonesia.
Buletin Ilmiah Litbang Perdagangan, 8(1), 93-116. doi: 10.30908/bilp.v8i1.89

Sholikhah, A. (2016). Statistik Deskriptif Dalam Penelitian Kualitatif. KOMUNIKA: Jurnal Dakwah Dan Komunikasi, 10(2), 342-362. doi: 10.24090/komunika.v10i2.953 